'MAIR, G. M. and MILLER, K., 2007. Design Imaging. In: T. INNS (ed.), Designing for the $21^{* t}$ Century: Interdisciplinary' Questions and Insights. Aldershot: Gower Publishing, pp. $246-259$

\section{Making Sense of the City: Representing the Multi-Modality of Urban Space}

Dr Raymond Lucas, Gordon Mair and Dr Ombretta Romice, (University of Strathclyde)

\section{Background}

This project emerged from a previous multidisciplinary Designing for the $21^{\text {st }}$ Century project - Design Imaging. ${ }^{1}$ The original project explored ways in which the full range of our senses could be exploited to assist with the design process. Discussions on multisensory and multimodal design led to a number of avenues being identified for further research. One in particular, that of representing urban space in a multisensory manner, was the subject of a successful second-round grant application from the Departments of Architecture and Design, Manufacture, and Engineering Management at the University of Strathclyde.

\section{Overview}

The urban environment is experienced through each of our senses. Despite this, urban design practices and urban representation have focused their attention on the visual. This project posits the thesis that a fuller urban environment can be designed by attending to multiple sensory modalities, by giving equal weight to the aural, the tactile, the olfactory, the gustatory, the haptic, the kinetic, and the thermal.

The research was conducted by a core research team based at the Department of Architecture and the Department of Design, Manufacture, and Engineering Management (DMEM) at the University of Strathclyde. The team was supported by a broad advisory board who met regularly to discuss the issues raised by the research in a cross-disciplinary environment. 
${ }^{2}$ LYNCH, K., 1960. $1990 \mathrm{ed}$. The Image of the City. Boston, MA: MIT Press.

${ }^{3}$ CULLEN, G., 1971. The Concise Townscape. Oxford: Architectural Press.

+ SADLER, S., 1998. The Situationist City. Boston, MA: MIT Press.
The lead investigators on the project were Gordon Mair, Wolfgang Sonne and Ombretta Romice, with Ray Lucas as Research Fellow. This research project couples the interest in multiple modalities with the form of the urban environment, and considers the possibility of designing for all the senses in unison rather than one or two.

Gordon Mair brought his experience of developing remote telepresence and sensing technologies to the project. Sonne applied his knowledge of urban form through history, while Romice contributed her knowledge of urban design practices and community engagement processes. Lucas brought his background in architectural design and research in anthropology of creativity, having a specialist interest in representational and notational techniques.

The advisory board contributed a great deal of further experience and knowledge to the project. Edward Edgerton (University of West of Scotland) provided insights from the field of environmental psychology alongside Simon Ungar (University of Surrey). John Marshall brought his knowledge of digital and emerging technologies to bear on the project themes from the point of view of his broad interests in art and design. The digital design studio of the Glasgow School of Art was represented by Mairghread McLundie. Parallel work in Experiential Landscape was described by Ian Simkins and Kevin Thwaites (University of Sheffield), including a notational system based on a theory of environmental experience of Centres, Districts, Thresholds, and Areas. Understanding the narrative and poetic potential of language was assisted by Nigel Fabb (English Literature, Strathclyde), while additional perspectives on the design process were added by Mike Anusas and Kevin Miller (DMEM, Strathclyde).

\section{Methodological approach: practical workshops}

Practical workshops were a key means of developing the project and allowed for a direct application of the research in a pedagogical context. The first workshop was conducted during a Diploma Year field trip to Berlin.

This first workshop focused on a variety of urban representation techniques and explored a number of inscriptive practices from Kevin Lynch's Imageability ${ }^{2}$ analysis through Gordon Cullen's Serial Vision ${ }^{3}$ and towards more esoteric graphics such as Laban Movement Notation and Drifts from the Situationist International. ${ }^{4}$ Students were asked to record 
their experiences of Berlin through these methods and others of their own devising, challenging traditional representational techniques and asking questions about what is important to presence in an environment, and what one attends to when drawing in a particular way.

The next workshop was more focused, having established the Sensory Notation System ${ }^{5}$ by this point. During a field trip to Dortmund, the second workshop deployed the Sensory Notation system for the first time, testing its application as a sketching tool. The workshop showed the system to be successful in the field, and relevant to the work of students, particularly when backed up by a text-based element. The notational system itself needs to be sufficiently simple and flexible; the main part of the system encourages the notator to perceive their environment in terms of each sensory system, how they interact and corroborate with one another and which qualities of the experience are important.
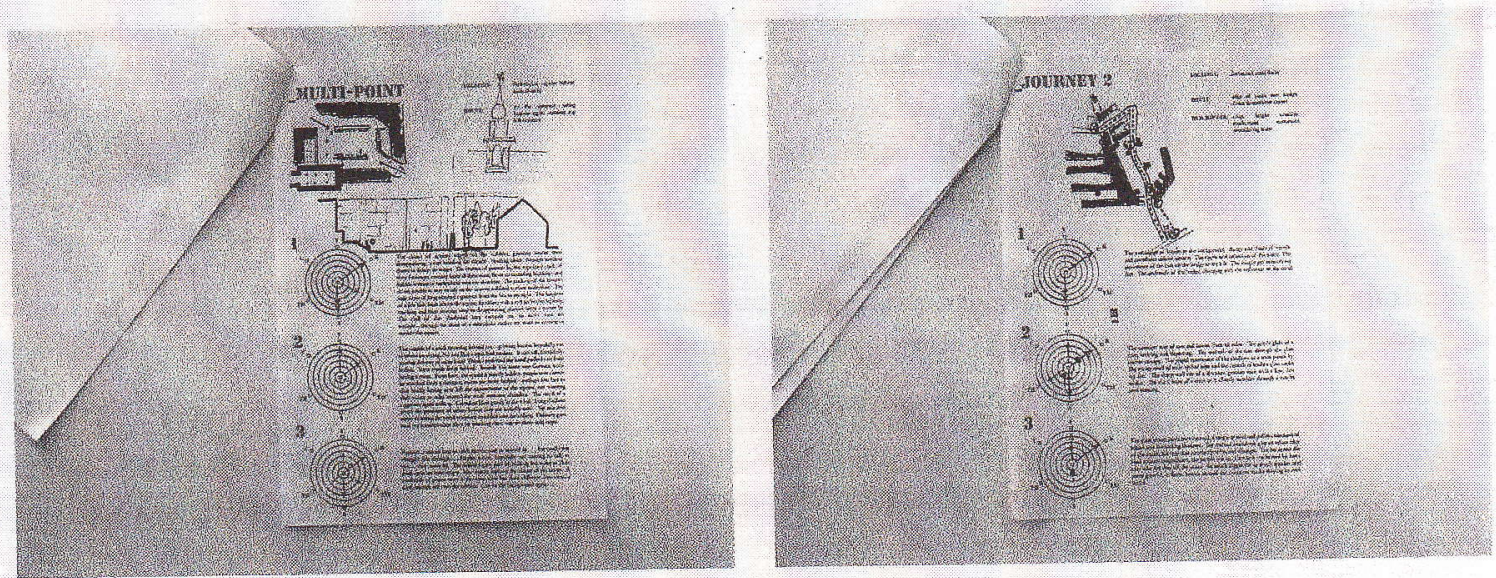

Figure 1, Example of work from the Dortmund workshop

A third workshop introduced the material to a different group - academics and $\mathrm{PhD}$ candidates in Social Anthropology at the University of Aberdeen. This workshop was part of a larger group of activities, all focused on how anthropologists can integrate graphic work into their ethnographic research.

The group were introduced to the broad idea of notation (as distinct from sketching or drafting) with a talk and peripatetic workshop asking each participant to record the qualities of someone else's movement based on some sample notations. The second day of the workshop concentrated on the Sensory Notation proper, and provided valuable data on the applicability of the notation, its ease of use and its flexibility with regard to more participatory and engaged forms of research. 

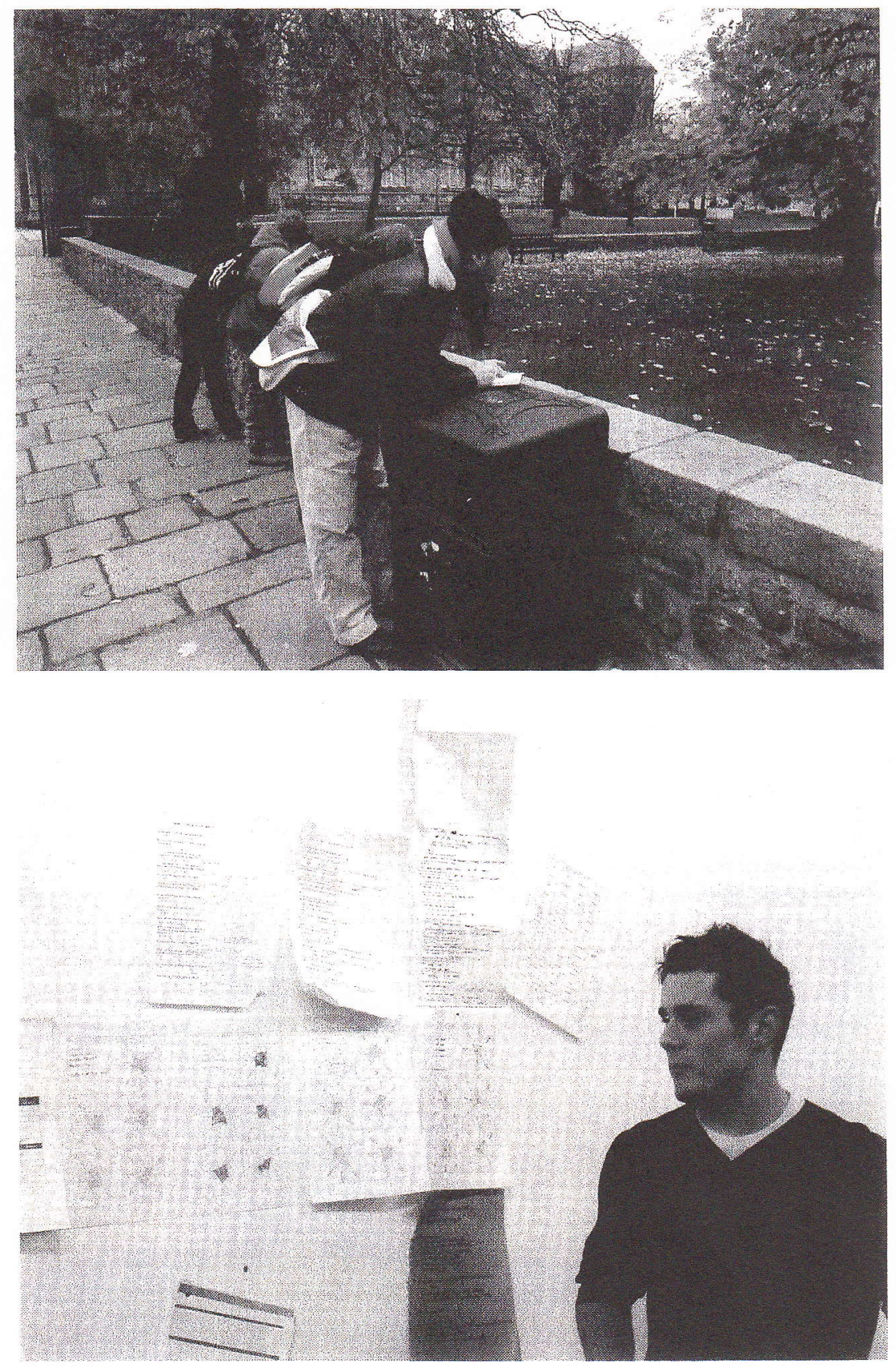

Figures 2 and 3

top to bottom

Figure 2, Using Sensory Notation with anthropologists from Aberdeen University exposed some of the potential uses of this descriptive method

Figure 3, Glasgow High Street workshop, showing comparative approaches to understanding the social and sensory nature of a street in Glasgow 
${ }^{5}$ LUCAS, R. and MAIR, G. (eds.), Sensory Urbanism Proceedings 2008, Glasgou, 8-9 Tanuary 2008. Edinburgh: Flâneur Press. Available at: $<$ http://www:lulu. com/content/paperbackbook/sensory-urbanismproceedings $/ 5273613>$.
The final workshop asked a cohort of sixty $5^{\text {th }}$ year Urban Design students to explore Glasgow's High Street. The group were divided into three: one group conducted a literature review, one group conducted interviews and the third group used Sensory Notations.

The point of the exercise was to encourage a multifaceted approach to site investigations, with the literature-based group coming up with different emphases and opinions to the other two groups. Each form of representation encourages a particular view of a site, each equally valid, but each with a different focus.

Within each group, the students were asked to collate results and arrive at a consensus about how they experienced the place. The three distinctive approaches to the space opened a discussion about the qualities of Glasgow High Street.

\section{Towards a sensory urbanism}

In January 2008, a conference on the theme of Sensory Urbanism ${ }^{5}$ was held. The aim was to bring a wide range of practitioners and academics together to discuss the approaches and implications of a multisensory approach to design in the urban environment. The conference addressed a number of themes, with the panels organised according to the scale being considered rather than divisions along disciplinary lines. This allowed for a discussion to emerge between the various academics and practitioners from fields such as architecture, urban design, product design, geography, cultural studies, fine art, performance and anthropology.

Several important issues emerged over the course of the conference and were crystallised during the plenary session which closed the conference.

Alternatives to vision as the primary sensory modality have the potential to be powerful critiques of the picturesque forms of aesthetics that have come to dominate architecture and urban design. By widening the scope if design to include the aural, haptic, kinaesthetic, olfactory, gustatory and thermal, we open design up to considerations of experience and temporality.

This temporalising impulse of the alternative sensory modalities can be most clearly understood with reference to the sense of sound. Sounds cannot be easily encapsulated by the totalising gaze, but must be understood in sequence and as events that have a particular duration. This is a challenge to the traditional forms of design representation such 
as the plan, which depicts geometric relationships between objects in space. This absolute relationship is dangerous, as it allows the designer to make assumptions that a space will always be the same, one moment to the next, one week to another, from season to season and over the course of years. The objectifying gaze is encultured into our design processes, and this is something addressed by delegates to the conference including Gregoire Chelkoff (CRESSON, Grenoble) and Mike Fedeski (Architecture, Cardiff). Both papers stress the need for a design environment which is available to be walked around and related to at 1:1 scale. Whilst there are limits to this approach in terms of cost and practicality, Professor Chelkoff spoke about one example his laboratory has built in order to test the observations CRESSON have made over the years with regard to the behaviour of sound in urban space.

The alternative of sound was presented in an innovative way by Min Feng Hsieh (Architecture, Edinburgh), who described his research investigating the ways in which musical perception can be turned towards architectural and urban space. This highlights the quality of attention in perception, challenging the passivity suggested by some deeply held scientific views of the senses. By attending to an experience in a deliberate way - for example, the way in which classical music has its own temporality outside that of the quotidien (and is described as auratic, producing an aura, by the likes of Adorno) - we can enhance our understanding and appreciation of an urban space.

These ties between perception and design were further cemented by the work of Ombretta Romice (Architecture and Urban Design, Strathclyde) with Edward Edgerton (Environmental Psychology, Paisley) in encouraging work between urban design and environmental psychology.

The alternative modalities also stress narrative in different ways. Again, as a reaction to the potentially totalising gaze, narrative is understood to be crucial to this experiential model of space. That issues of space and place are still up for grabs even after influential texts such as those by Lefebvre, de Certeau and recent work by Ingold is testament to the power of inscriptive practices such as plan, section, elevation and perspective not only as representations, but also as theories of space in themselves.

Alternatives to this practice were presented by Gerald Davies and Carl Lavery (Theatre Studies, Lancaster) as well as Naomi Stead (Advanced Cultural Studies Institute, Sweden and University of Technology, Sydney), presenting the written word as one alternative means of describing and working with space. Alternatives to this were explored by my own 
paper, describing the process we are engaged in at present, designing a notation for the full sensory experience of place (attention and training of perception is another key element of this). Our plenary speaker, Professor Simon Unwin (Department of Architecture, Dundee), spoke about the power of threshold within a phenomenological framework. This most fundamental of architectural acts is rich with experience, demanding the full attention of the designer and a response to the breadth of sensory stimuli involved in the simple act of passing from one place to another. Narratives which encourage participation were described by Minty Donald (Glasgow School of Art) with an account of an installation at Glasgow's Tramway Gallery which involved the bodily engagement of visitors moving carts over the tram lines still existing within the gallery, a former depot. These were synchronised with a now-defunct tram route filmed and projected on to the walls. Personal narratives and remembrances could then be woven into the installation.

Indeed, fine art and its related disciplines were to feature prominently, providing some innovative examples of multisensory spaces and the implications of such environments. Papers on this theme included those by Kirsty Stansfield (Dundee), Malca Mizrahi (Bartlett) and Suzanne Ewing (Edinburgh).

The practicalities of design for all the senses produced a number of fascinating papers. An issue which emerged from papers such as those by Jasmien Herssens (Hasselt), Harvey Ward Turner and Laura Lewis (Mugstain Design), Hendrik Schifferstein, Marieke Sonneveld and Geke Ludden (Delft) and Peter Howell and Julia Ionides (Dogrose Trust) was the Utopian impulse of such endeavours. There is a recognition that multisensory design is difficult and an ideal towards which one may strive. It is understood, however, that reaching that ultimate destination is probably not possible, but that the drive towards it can reap fantastic rewards, particularly when designing with disability and sensory impairment in mind. Herssens described the subtle differences in approach between Universal Design and Barrier Free Design, defining Universal Design as a movement which recognises a broad range of capabilities and attempts to design for those. Barrier Free Design focuses on the disability and attempts to design the problem out. The built environment must adapt itself to us and our needs.

The issue of safety is closely related both to the urban focus of the conference and several of the papers on the senses. Some explicitly tackled this issue, such as Akkelies van Nes (Delft), who turned Space Syntax methodology to the senses and perceptions of safety. Indeed, a rich vein of 
work on the senses emerged from the Space Syntax community, including a paper by Akira Ohta, Rim Meziani and Toshyuki Kaneda (Nagoya) analysing movement within pedestrian areas. Other papers addressing safety included one by Julian Richard (Charles University in Prague) who spoke on the often overlooked aspect of the city, the night, and how it can throw visual stimuli into reverse as lit windows call attention to buildings, rather than the mass of walls, and the heightening of the non-visual senses when such stimuli are deprived.

The very technology of multisensory space was another important issue, addressed by speakers including Gordon Mair (DMEM, Strathclyde) and Seb Jouan (Arup Acoustics). This thread of the conference indicates some of the possible ways forward in crafting sensory environments more carefully as well as examining some of the implications of this technology. Understanding and recording forms the first part of the process, and by attempting to reproduce and understand human perception, a great deal is learned about it: how the ear may differ from a microphone, for example, and the complex technology required to replicate that experience of sound. This recording makes the experience available for more detailed analysis, of course, and avoids some of the potential vagueness of the phenomenological approach.

\section{Sensory Urbanism exhibition}

The conference held a parallel exhibition stream curated by Ray Lucas, recognising that the traditional academic paper has limits, particularly when discussing sensory experience.

Installations included Fiona ni Mhaoilir's Heavy Shower, consisting of plaster casts of bricks suspended from the ceiling. The materiality plays with the expectations of the audience. Timothea Kolouri installed her work, The Spiral, in the exhibition space. This work used fabric to create varying senses of enclosure and openness within a small space. The path created was visual, tactile and kinetic.

Video installations also featured, with Wael Fahmi exhibiting a work concerned with Cairo's 'contested spatiality' by replacing the flâneur's gaze with a roving video camera. The various attractions and signs are explored in this film about distracted navigation. Film-makers Lewis Paul and Sarah Taylor also participated by showing their films Generational Experience and No Ball Games, which look at how different groups of people understand and perceive their worlds differently. 


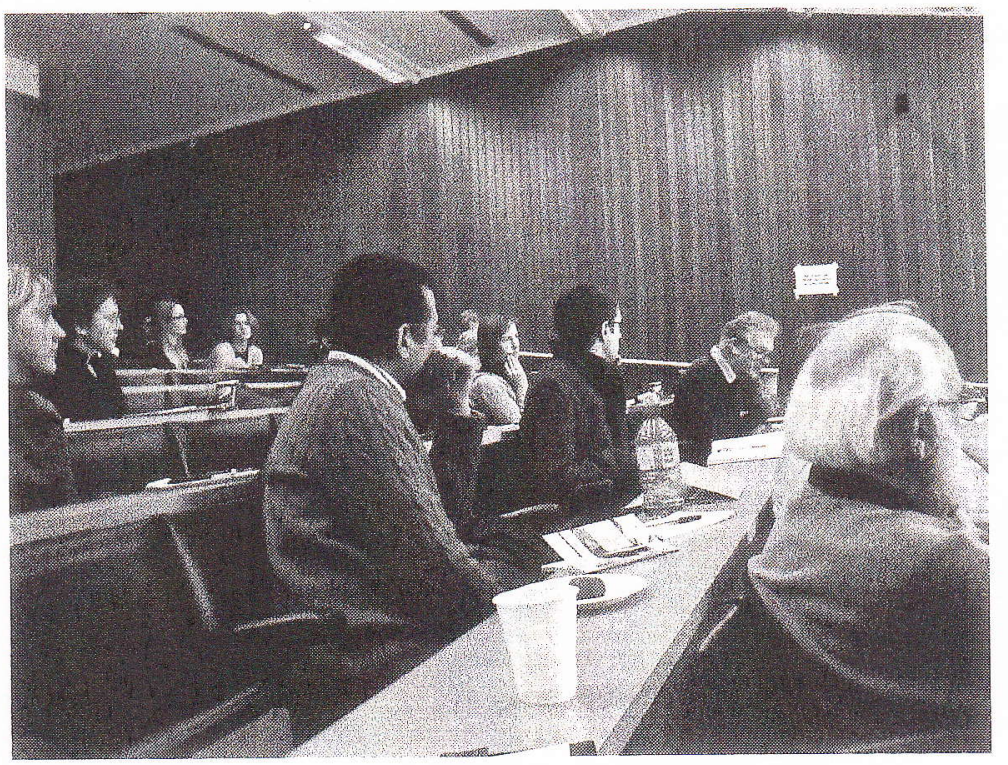

Figures 4 to 6

top to bottom, left to right

Figure 4, Sensory Urbanism conference

\section{Figure 5, Sensory Urbanism}

exhibition, showing Heavy Shower by Fiona ni Mhaoilir

Figure 6, Scnsory Urbanism

exhibition, showing The Spiral by

Timothea Kolouri
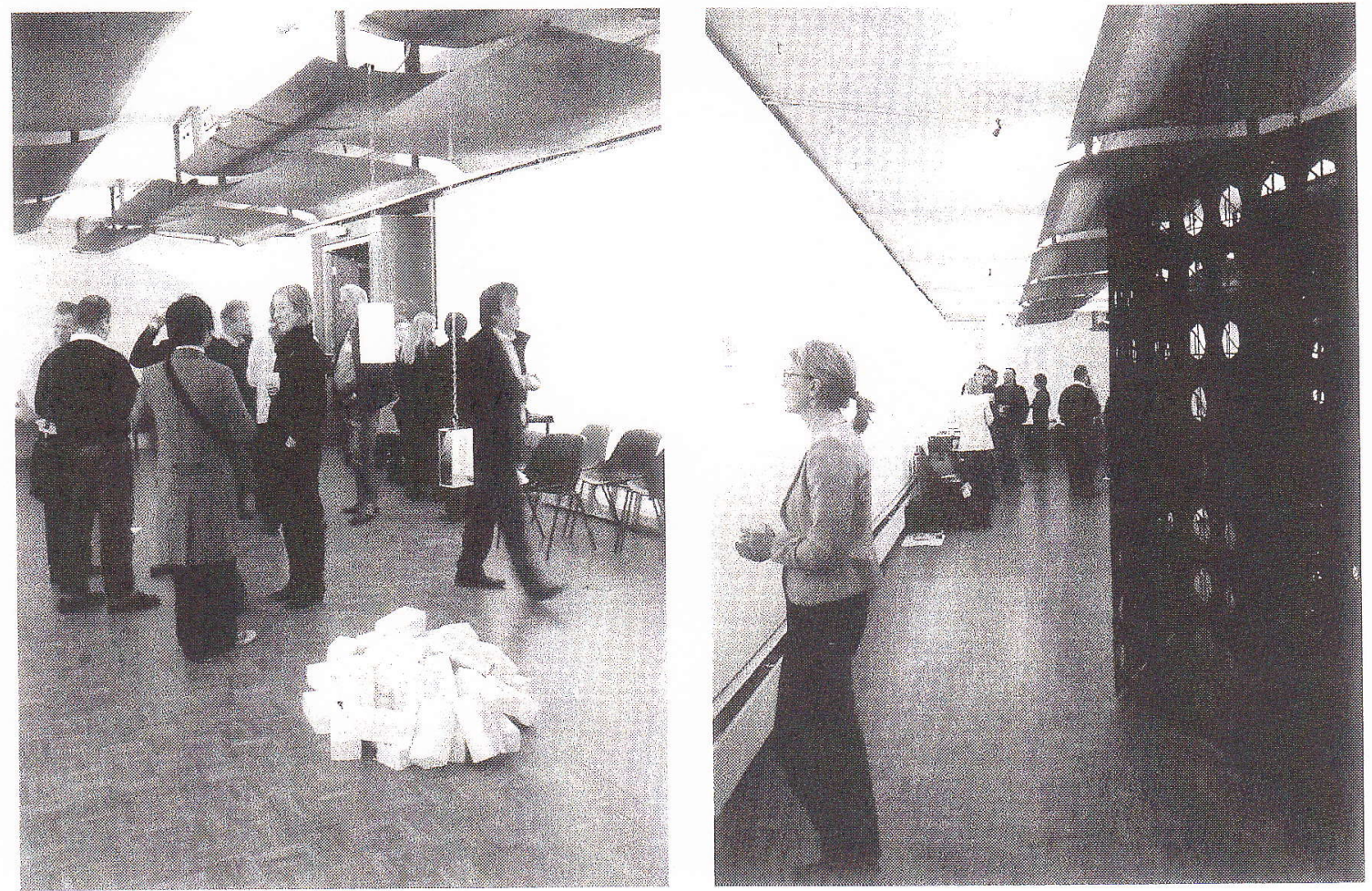
6 STICKELLS, L. (ed.), forthcoming. Sensory Urbanism. Special Issue: Architectural Theory Review Special Isstie: Sensory Urlanism. (14)2.

INTERNATIONAL ASSOCIATION OF PEOPLEENVIRONMENT STUDIES, 2008. Available at: <http:// wwwiaps-association.org activities-remit/networks/ urban-morphology-andrepresentation/ $>$.

${ }^{8}$ LABAN, R, and ULLMAN, L., 1979. Effort. London: Macdonald and Evans Led.
Stephanie Brandt, Ann Nisbet and Matteo Melioli produced graphic works in tune with the conference themes. Melioli showed Ghost Spaces which deployed the medium of architectural drawing to explore the concept of echo, extending the everyday reverberance of acoustic conditions to the very spaces he encountered in Venice. The results are architectural fantasies exploring a flip-side of these grand, well-known buildings. Ann Nisbet presented works from Weaving Through Space which challenged traditional materiality by introducing the technique of weaving to glass, metal, timber and concrete. Stephanie Brandt's work looked at the idea of habit in On Rubbish. This series of photographs was structured as a dialogue considering the concepts of 'rubbish' and 'architecture'.

Continuing the debate: Urban Representation and Morphology Network, ATR Special Issue and Sensory Urbanism proceedings

The conference has been essential in laying the groundwork for a theory of Sensory Urbanism. This is explored in the forthcoming special issue of Architectural Theory Review (ATR), ${ }^{6}$ the conference proceedings, ${ }^{5}$ and the establishment of the International Association People-Environment Studies (IAPS) Urban Representation and Morphology Network, the latter network ensuring a continued life for the project. Establishing the network allows the concerns and issues raised by the research project to be tackled by a cross-disciplinary group of academics and practitioners in the fields of urban design and environmental psychology. The inaugural meeting of the network is scheduled for the IAPS congress taking place in 2010.

\section{New Knowledge and Understanding: Sensory Notation}

The key outcome of the project is the Sensory Notation system and Pattern Book. The approach of Sensory Notation was developed through the course of the research project, from early schemas based on the work of influential dance theorist Rudolf von Laban. ${ }^{8}$ The complexities of the initial matrix notations allowed for complex and internally consistent notations of sensory experience. It was clear, however, that the system had similar difficulties to Laban Notation - that is, it was difficult to learn in the first instance.

The eventual notation consisted of three parts, as it became apparent that no single representation could adequately achieve our aims of describing sensory experience in a manner accessible to the design process. 
"PEREC, G., 1974. (1997 ed.) Species of Spaces and Other Pieces. London: Penguin, p. 51 .

10 GIBSON, J. J., 1966. The Senses Considered as Perceptual Systems. Westport, CT: Greenwood Press.
Discussions within the advisory board revolved around the use of language in describing sensory experience, the act of simply naming a stimulus giving a powerful shorthand to further description. To this end, we engaged with the work of writer Georges Perec, who, writing on the descriptive process, advised the aspiring writer to:

"Observe the street, from time to time, with some concern for system perhaps.

Apply Yourself. Take your time.

Note down the place: the terrace of a cafen near the junction of the Rue de Bac and the Boulevard Saint-Germain

the time: seven o'clock in the evening

the date: 15 May 1973

the weather: set fair

Note down what you can see. Anything worthy of note going on. Do you know how to see what's worthy of note? Is there anything that strikes you?

Nothing strikes you. You don't know how to see. You must write about out it more slowly, almost stupidly. Force yourself to write down what is of no interest, what is most obvious, most common, most colourless. ${ }^{19}$

This flatness of writing, concentrating on the quotidien, even banal, nature of a scene, became a core element of the Sensory Notation system. Each notation is accompanied by a stream of consciousness-style piece of writing, an account of a space or journey. This is contextual, tied to a particular time of day, a particular season, a set of weather conditions.

The notation itself needed to approach the senses together - a whole sensorium. To this end, we required a taxonomy of the senses appropriate to the description of the urban realm. The classical notion of five senses of sight, hearing, smell, taste and touch is a useful concept, but one which can hold too much sway, being used in an uncritical, unchallenged manner. The work of theorist James Gibson, ${ }^{10}$ who straddles the disciplines of psychology and phenomenology, provided the project with a model of the senses which was active and seeking stimulation. Rather than understanding the senses as passive receptors, Gibson argues that the senses are attentive, constantly looking for something to understand.

Gibson's perceptual systems are also deeply contextual. Gibson argues against the experimental model of lab-based investigations into the senses, stating that context is hugely important to how we make sense of the world through our sensory engagement with it. 
From this starting point, we identified six registers of perception important to the urban context of our project. Some of these were clearly borrowed from both Gibson and the classical Western notion of the five senses: the visual system, the auditory system. Other perceptual systems needed to be divided up a little differently. The sense of touch, for example, commonly includes our sensation of temperature, touch, and even movement. Each of these sensations is important to our experience of urban space, so the Sensory Notation system deals with the tactile system, kinetic system and thermal system. Finally, the two 'chemical' senses of taste and smell can be considered as one perceptual system for our study, giving us the chemical system.

This main graphic step of the Sensory Notation system charts a deceptively simple concept: the sensory priority as experienced in a given place. By saying which senses are dominant we can begin to build a picture of how we feel about a place, what affects us the most about it. From a series of these notations, we can begin to build a picture of urban spaces such as squares or streets, as well as to chart a longer route through the city or town.

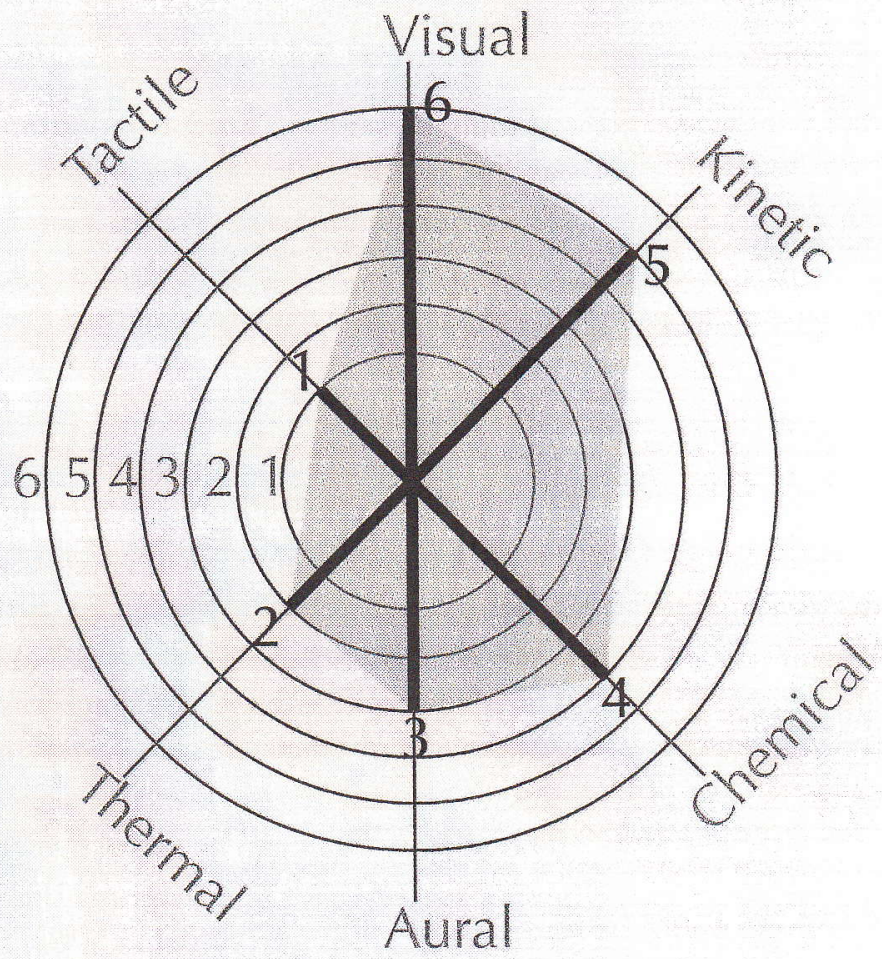

Figure 7, Sensory Notation priority chart 
13 FOUNDATION LE CORBUSIER, (ed.), 1982 Le Corbusier Sketchbooks: Volumes 1-4. Boston, MA: MIT Press.

12 BERGEIJK, H., HAUPTMAN, D. and HERTZBERGER, H., 1998. Herman Hertzberger: Notations. Rotterdam: NAi Publishers.
That this is a low-tech, distinctly subjective and experiential process is clear. The closest analogy would be with the architect's sketch-book, ${ }^{11,12}$ where visual experiences are recorded for future reference, to be understood and deployed in a later design. When making these sketches and developing a fundamentally architectural understanding of space, the architect needs no more than their own attentiveness and something to draw with. Deploying complex sensing technologies ran counter to our intentions in this regard, as we would begin to concentrate on what could be recorded. There is, after all, a huge difference between actual vision and what is recorded by a camera, or even the best binaural recording as compared to the shifting attention of a listener.

The notation is supplemented by descriptive language, a finite set of descriptive terms to give a quick idea of what is happening in a given space. These descriptors are chosen in pairs and are deliberately devoid of judgement and metaphor. The initial descriptive narrative allows for the relative merits of a place to be addressed, so the descriptors can remain neutral to this.

The sensory notation is developed with additional marks to describe the temporal aspects of each stimulus, noting the repetition, singularity, ambience or other qualities, as well as arcs showing the corroboration of multiple senses. This corroboration is particularly important as a way of enriching the sensory environment, as it reinforces the presence of a stimulus through more than one channel. This serial notation allows for the diagnosis of an existing context, showing up spaces which are too heavily focused on one sense, or distinctly lacking in stimulation for another sense. This sensory audit can be useful in establishing an appropriate response to the site. The diagrams can be read together, allowing for a quick grasp of a situation, a larger diagram such as those found in the study of Tokyo indicating a place where every sense is overstimulated. A small diagram, typically found in a shopping mall, describes a place where there is too little sensory data. Spikes on the chart show a focus on a particular sense, such as a windswept plaza in Dortmund, where the public space was out of scale with the thermal dimensions of the place.

This sensory audit can be useful in establishing an appropriate response to the site. The diagrams can be read together, allowing for a quick grasp of a situation, a larger diagram, such as those found in the study of Tokyo, indicating a place where every sense is overstimulated. 

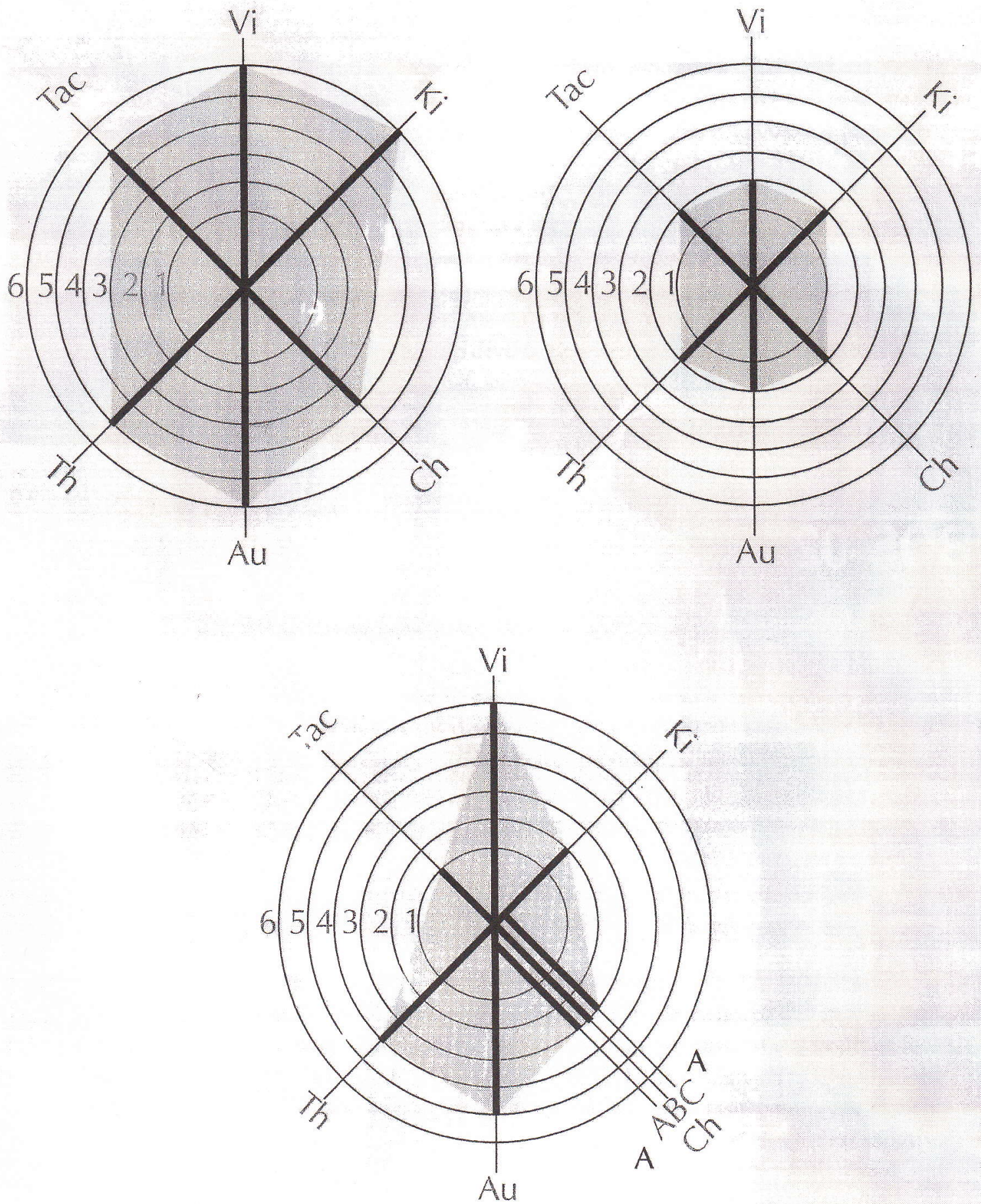

A: Meat

B: Cheese

Figure 8, Sensory Notation samples

C: Bread 

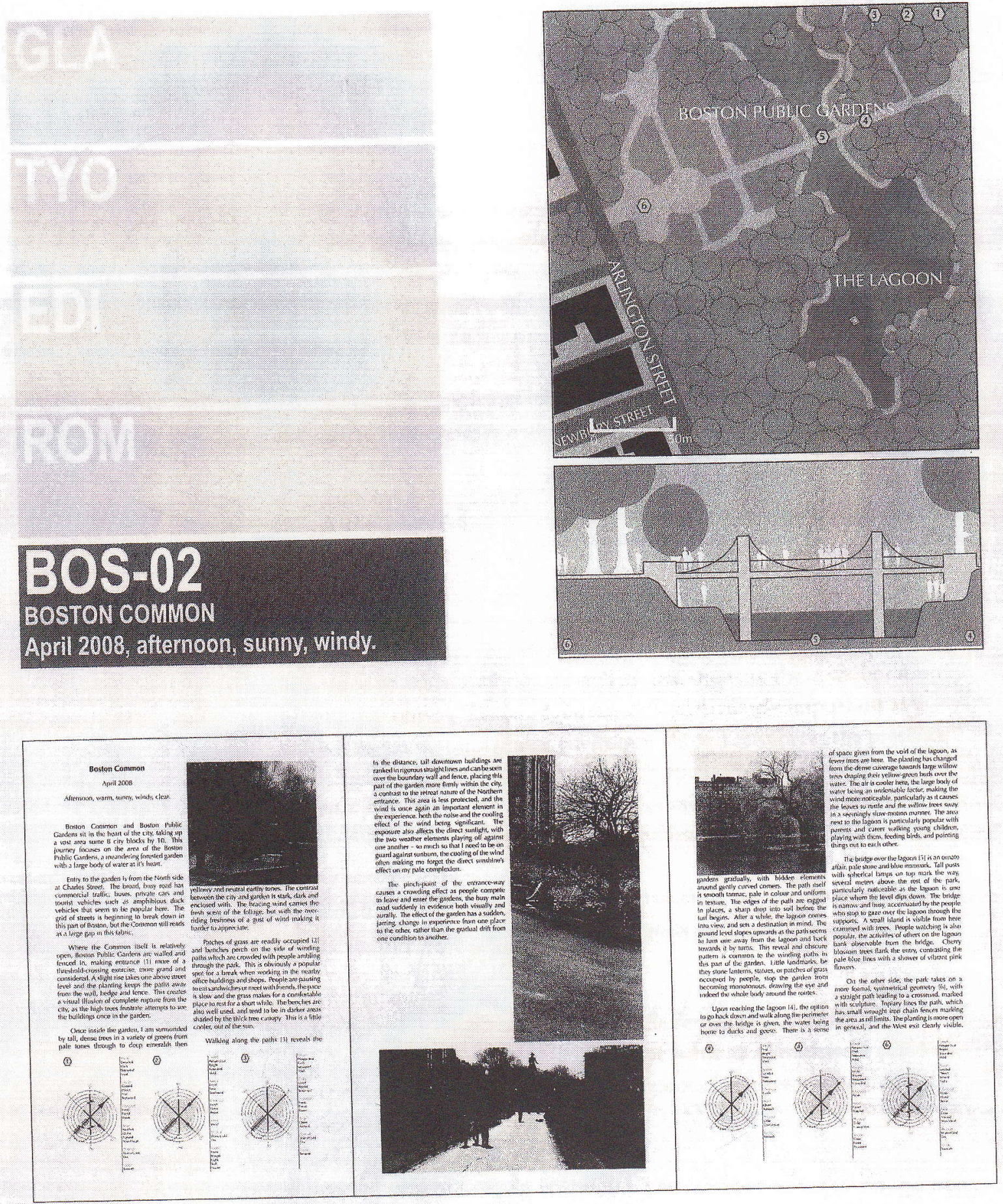

Figure 9, Sensory Notation Pattern Book example 
13 LUCAS, R., 2009. Sensory Notation Handbook. Edinburgh: Flàneur Press.

1.4 ALEXANDER, C. et al., 1977. A Pattern Language. New York: Oxford University Press.
The publication of the Sensory Notation ${ }^{13}$ is accompanied by a pattern book in the tradition of Christopher Alexander's famous Pattern Language. ${ }^{14}$ This section includes ten sites from a number of contrasting cities: Tokyo, Boston, Rome, Jakarta. Additional cities will be added to this pattern book in due course, but the pattern book is intended as a model for the architect's and urban designer's own travel sketches. The notation is a powerful tool for describing the full sensory experience of a place. By building up a stock of these notations and narratives, the designer can use these spaces as a model for further development.

As such, an architect can refer to the pattern book for both inspiration and useful models to help develop design strategies. Rather than attempting to replace existing design methodologies, the Sensory Notation aims to add an additional layer of information to existing practices, be they based in the design studio, in the field, or in community engagement processes.

\section{Conclusion}

There is a great deal of power in representation. The form a representation actually takes is particularly telling on the thought processes involved, as these are far from neutral: representation is understanding something by reproducing it. In much the same way as a painter, no matter how much realism is attempted, we cannot hope to entirely capture every detail in a scene; this means that choices must be made. The choices of what to leave in and what to omit are central to all acts of representation. This problematises our entire endeavour of producing a notational system for the non-visual sensory modalities. This problematic does not, of course, mean that we ought to abandon the project, but rather that we should remain mindful that every decision on how to represent something influences what we actually record and depict.

Our proiect asks if there is something inherent to design that marks it out as a visu . I discipline. The majority of tools we use to design are visual; drawings and models are all representations of the way something looks on one level. Of course, there is more to the traditional representations than this, and drawings, such as plans, depict the relationships and thresholds between areas; section drawings tell us a great deal about volumes and massing, but the information is fundamentally visual. One reason for this is the totality offered by visual representation. 